\title{
Dysglycemia in Critically III Patients: Common Problems and Future Direction
}

Sarvin Sanaie ${ }^{1}$, Ata Mahmoodpoor ${ }^{2 *}$

1. Assistant professor of Nutrition. MD. PhD, Tuberculosis and Lung Disease Research Center, Tabriz University of Medical Sciences, Tabriz, Iran

2. Professor of Anesthesiology, Fellowship of critical Care Medicine, Cardiovascular Research Center, Tabriz University of Medical Sciences, Tabriz, Iran

The management of blood glucose (BG) in the critically ill became a topic of great interest following the publication of the landmark single-center surgical ICU study targeting euglycemia ( 80 to $110 \mathrm{mg} / \mathrm{dL}$ ) in Leuven, Belgium, in 2001 (1). This study resulted in thousands of protocols and guidelines promoting 'tight' BG control. The failure to show the same results and high incidence of hypoglycemia in following trials have resulted in controversy in blood glucose management in critically ill patients. Analysis of dysglycemia in critically ill patients should include markers of three domains: hyperglycemia, hypoglycemia, and glycemic variability $(2,3)$. Thus, hyperglycemia, hypoglycemia, and blood glucose variability should all be regarded as independent predictors of adverse outcomes in critically ill patients. Agus et al., in their multicenter study (4), showed that critically ill children with hyperglycemia did not benefit from strict glycemic control to a target glucose of $80-110 \mathrm{mg} / \mathrm{dL}$ compared to $150-180 \mathrm{mg} / \mathrm{dL}$ and patients in lower treatment target showed an insignificant 90-day mortally rate compared to other group. There are so many reasons to describe these controversies: In LEUVEN III study (5), despite a $25 \%$ hypoglycemia incidence, tight glycemic control had a significant treatment effect; nevertheless, in Agus et al. study, despite a lower incidence of hypoglycemia, treatment effect was not significant. The reasons can be explained with the fact that first trials were single centered open label studies which were terminated at early stages of the study because of observed benefits which may have exaggerated the treatment effect. Also, the observed difference was found in subgroup analysis which could have been due to chance factor. Findings from RCTs conducted on critically ill adults and children strongly suggest that the largest benefit for blood glucose control can be expected if the difference in blood glucose concentrations between the study groups is large and if the study is done in a single-centre setting where the blood glucose management is tailored to the local treatment habits. Consequently, we could not compare those single centered trials which are not externally validated with high level of adherence to protocols, lower time to target range, higher time in target

\section{Corresponding author:}

Ata Mahmoodpoor

Tabriz University of Medical Sciences, Tabriz, Iran

E-mail: amahmoodpoor@yahoo.com Phone: +989141160888

Receive date: 2017-03-01 | Accept date: 2017-04-26 | Publish date: 2017-05-05

DOI: 10.7575/aiac.abcmed.17.05.03.01 
range with multi centered trials with a low level of adherence to protocol higher time to target range, lower time in target range and a totally different method of energy supplementation. Finally, the era of 'one size fits all' in regard to glycemic targets in the critically ill seems to be over. We should also consider the correct and earlier diagnosis of patients, their glycemic status and preadmission glycemic control individually (6). Future trials should consider the discrepancies accounting for controversial points like nutritional status of patients, glucose monitoring methods (7) and insulin titration method.

\section{References}

1. Van den Berghe $G$, Wouters $P$, Weekers F, Verwaest C, Bruyninckx F, Schetz $M$, Vlasselaers $D$, Ferdinande $P$, Lauwers P, Bouillon R. Intensive insulin therapy in critically ill patients. N Engl J Med. 2001 Nov 8; 345(19):1359-67.

2. Mahmoodpoor A, Hamishehkar H, Beigmohammadi M, Sanaie S, Shadvar K, Soleimanpour H, Rahimi A, Safari S. Predisposing Factors for Hypoglycemia and Its Relation With Mortality in Critically III Patients Undergoing Insulin Therapy in an Intensive Care Unit. Anesth Pain Med. 2016 Jan 31;6(1):e33849. doi: 10.5812/aapm.33849. eCollection 2016 Feb.

3. Mahmoodpoor A, Ali-Asgharzadeh A, Parish M, Amir-Aslanzadeh Z, Abedini N. A comparative study of efficacy of intensive insulin therapy versus conventional method on mortality and morbidity of critically ill patients. Pak J Med Sci 2011; 27: 496-9

4. Agus MS, Wypij D, Hirshberg EL, Srinivasan V, Faustino EV, Luckett PM, Alexander JL, Asaro LA, Curley MA, Steil GM, Nadkarni VM; HALF-PINT Study Investigators and the PALISI Network.Tight Glycemic Control in Critically III Children. N Engl J Med. 2017 Feb 23;376(8):729-741. doi: 10.1056/NEJMoa1612348.

5. Vlasselaers D, Milants I, Desmet L, Wouters PJ, Vanhorebeek I, van den Heuvel I, Mesotten D, Casaer MP, Meyfroidt G, Ingels C, Muller J, Van Cromphaut S, Schetz M, Van den Berghe G. Intensive insulin therapy for patients in paediatric intensive care: a prospective, randomised controlled study. Lancet. 2009 Feb 14;373(9663):547-56. doi: 10.1016/S0140-6736(09)60044-1.

6. Mahmoodpoor A, Hamishehkar H, Shadvar K, Beigmohammadi M, Iranpour A, Sanaie S. Relationship between glycated hemoglobin, Intensive Care Unit admission blood sugar and glucose control with ICU mortality in critically ill patients. Indian J Crit Care Med. 2016 Feb;20(2):67-71. doi: 10.4103/0972-5229.175938.

7. Mahmoodpoor A, Hamishehkar H, Shadvar K, Sanaie S, Iranpour A, Fattahi V. Validity of bedside blood glucose measurement in critically ill patients with intensive insulin therapy. Indian J Crit Care Med. 2016 Nov;20(11):653657. 